\title{
PENERAPAN BUDAYA KERJA KAIZEN DI PT X KABUPATEN BANDUNG BARAT
}

\author{
Budi Prasetiyo, Ryan Supu Tauhid \\ Fakultas Ekonomi Universitas Nasional Pasim \\ Jalan Dakota No 8a Sukaraja Bandung \\ Email: nararitelclub@gmail.com
}

\begin{abstract}
Kaizen is a Japanese culture that means continuing to improve and improve quality in the workplace. This culture is applied by many Japanese companies in the world, especially manufacturing companies. ISO 9001 is a quality management control system (Total Quality Management / TQM) issued by the Internatinal Organization for Standardization. ISO 9001 emphasizes for organizations starting from top management to lower level in carrying out continuous improvement and improvement of work quality. The auxiliary tool used in this research is Quality Control Circle (QCC) which uses the PDCA concept and 7 tools. The QCC method is a method that can be used to control product quality and reduce the number of defective products. The results of this study are that the Kaizen work culture has not run effectively even though the impact on productivity and employee performance is very influential and from the results of this QCC it is evident that with the change in the new Operational Procedure Standards it can reduce the total percentage of defective goods compared to the previous period
\end{abstract}

Keywords: Kaizen, ISO 9001, Total Quality Management, PDCA, 7 Tools, Quality Control

\begin{abstract}
Abstrak
Kaizen adalah budaya Jepang yang berarti terus meningkatkan dan meningkatkan kualitas di tempat kerja. Budaya ini diterapkan oleh banyak perusahaan Jepang di dunia, terutama perusahaan manufaktur. ISO 9001 adalah sistem kontrol manajemen kualitas (Total Quality Management / TQM) yang dikeluarkan oleh Organisasi Internasional untuk Standardisasi. ISO 9001 menekankan untuk organisasi mulai dari manajemen puncak ke tingkat yang lebih rendah dalam melakukan perbaikan dan peningkatan kualitas kerja yang berkelanjutan. Alat bantu yang digunakan dalam penelitian ini adalah Quality Control Circle (QCC) yang menggunakan konsep PDCA dan 7 alat. Metode QCC adalah metode yang dapat digunakan untuk mengontrol kualitas produk dan mengurangi jumlah produk yang rusak. Hasil penelitian ini adalah bahwa budaya kerja Kaizen belum berjalan secara efektif walaupun dampaknya terhadap produktivitas dan kinerja karyawan sangat berpengaruh dan dari hasil QCC ini terbukti bahwa dengan perubahan dalam Standar Prosedur Operasional yang baru dapat mengurangi persentase total barang cacat dibandingkan dengan periode sebelumnya
\end{abstract}

Kata kunci: Kaizen, ISO 9001, Manajemen Kualitas Total, PDCA, 7 Alat, Kontrol Kualitas 


\section{PENDAHULUAN}

Saat ini dunia industri memegang peran penting dalam era pembangunan di Indonesia. Munculnya industri kecil dan besar baik perusahaan swasta maupun perusahaan negara akan menjadi tonggak dalam memajukan bangsa. Hanya perusahaan yang memiliki competitive advantagetinggi dalam menghasilkan kualitas produk dan memiliki sistem produksi yang efisien dapat bertahan dan berkembang dalam kondisi persaingan yang ketat. Kedua hal tersebut merupakan tolak ukur kinerja perusahaan yang sangat vital bagi perusahaan dalam memperoleh keuntungan yang optimal.

Peningkatan dan pengendalian mutu produksi memerlukan komitmen yang tinggi dalam melakukan perbaikan khususnya dari aspek manusia (motivasi) dan aspek mesin (teknologi). Pengendalian Mutu Terpadu merupakan suatu pendekatan manajemen modern gunadalam menjalankan suatu usaha dengan mengoptimalkan daya saing perusahaan melalui continuous improvement atas produk yang dihasilkan.

PT X adalah perusahaan yang bergerak di bidang manufaktur yang aktivitas utamanya adalah melakukan proses pengolahan bahan baku menjadi barang jadi berupa tekstil yang siap untuk dipasarkan. Salah satu proses produksi tekstil tersebut adalah melalui proses pencelupan kain mentah (grey) menjadi kain warna. Adapun jenis tekstil yang dihasilkan diantaranya adalah produk polyester, rayon, dan acrylic. Agar dapat menghasilkan barang yang berkualitas baik, PT X menerapkan pengendalian kualitas mulai dari kualitas bahan baku, mesin, tenaga kerja, dan bahan baku pendukung lainnya, agar barang yang dihasilkan memiliki kualitas tinggisehinggadapat bersaing dalampasar lokal maupun international, serta dapat menekan kerugian yang diakibatkan oleh kerusakan pada produk tersebut.

Dalam proses produksi yang telah dilaksanakan oleh PT X, khususnya pada Departemen D, pada proses pencelupan tekstil kadangkala sering terjadi hambatan-hambatan yang menyebabkan kerusakan pada produk atau penyimpangan-penyimpangan pada barang yang diproduksi sehingga produk tersebut tidak dapat dipasarkan kepada konsumen. Oleh sebab itu, agar dapat mengurangi penyimpangan tersebut, PT $\mathrm{X}$ diharapkan rutin mengadakan evaluasi pada pengendalian dan perbaikan mutubarang yang berlangsung saat ini. Konsep Budaya Kerja Kaizen merupakam salah satu bentuk evaluasi manajemen mutu khususnya dalam aspek produksi yang bertujuan dapat meningkan mutu produksi.

Kaizen adalah budaya yang telah lama diimplementasikan oleh banyak perusahaan di Jepang dan dapat memberikan perubahan dan perbaikan kinerja yang sangat besar bagi perusahaan. Kaizen mungkin tidak asing bagi sebagian orang. Secara harafiah, kaizendibentuk dari dua suku kata yaitu "kai" yang artinya merubah dan "zen" yang artinya lebih baik. Secara sederhana, pengertian kaizen adalah usaha perbaikan secara terus menerusagar menjadi lebih baik dari kondisi sekarang. Namun ada juga yang menyebutnya dengan "Kaizen Teian" yang artinya "kaizen" berarti perbaikan secara terus menerus, sementara "teian" berarti sistem. Jadi, Kaizen Teian merupakan sistem dalam suatu perusahaan yang komprehensif yang dilakukan dalam rangka melakukan perbaikan secara terus menerus agar dapat mencapai kondisi yang lebih baik dari saat ini, sehingga dapat membawa spirit baru dalam setiap perusahaan.

Penerapan kaizen bisa dilakukan di awal proses produksi, pada saat proses produksi, hingga proses akhir barang tersebut disimpan di gudang dan siap di kirim ke customer. Sehingga barang yang dihasilkan memiliki nilai jual yang tinggi dengan kualitas yang baik. Selain itu penerapan kaizen dapat menurunkan biaya produksi dengan cara menurunkan jumlah barang yang rusak atau NG (Not Good).

Dengan diterapkannya kaizen di PT X khususnya pada Departemen D pada proses pencelupan tekstil, dapat menghilangkan hambatan-hambatan yang menyebabkan kerusakan atau penyimpangan-penyimpangan pada produk yang dihasilkan, serta meminimalisir pemborosan-pemborosan yang tidak perlu karena menimbulkan biaya-biaya yang menyebabkan berkurangnya profit dan 
meminimalkan kemungkinan timbulnya cacat pada produk yang dihasilkan.

Berdasarkan penjelasan di atas, maka judul yang dapat penulis ambil dalam penelitian ini adalah "Penerapan Budaya Kerja Kaizendi PT X Kabupaten Bandung Barat".

Oleh karena itu penelitian ini menetapkan identifikasi masalah yang terdiri dari Bagaimana Penerapan Budaya Kerja Kaizen pada Departemen D PT X di Kabupaten Bandung Barat, Bagaimana cara untuk mengatasi kendala-kendala dan hambatanhambatan dalam penyelesaian masalah menggunakan konsep kaizen pada Departemen D PT X di Kabupaten Bandung Barat.

\section{TINJAUAN PUSTAKA}

\section{Kualitas}

Lupiyoadi (2014:63) berpendapat bahwa Kualitas adalah perpaduan antara sifat dan karakteristik yang menentukan sejauh mana keluaran dapat memenuhi persyaratan kebutuhan pelanggan, jadi pelanggan yang menentukan dan menilai sampai seberapa jauh sifat dan karakteristik tersebut memenuhi kebutuhannya.

Kualitas menurut Garvin dan Davis dalam Nasution (2015) adalah suatu kondisi dinamis dimana yang berhubungan dengan produk, manusia/tenaga kerja, proses dan tugas, serta lingkungan yang memenuhi atau melebihi harapan pelanggan atau konsumen.

\section{Total Quality Management}

Menurut Edward Sallis (2015), Total Quality Management adalah sebuah filosofi perbaikan secara terus menerus yang dapat memberikan seperangkat alat praktis kepada setiap institusi pendidikan yang memenuhi kebutuhan, keinginan dan harapan para pelanggannya untuk saat ini dan masa yang akan datang.

Menurut Ishikawa dalam Nasution (2015) istilah Total Quality Management diartikan sebagai perpaduan semua fungsi manajemen, semua bagian dari suatu perusahaan dan semua orang ke dalam falsafah holistik yang dibangun berdasarkan konsep kualitas, teamwork, produktivitas, serta kepuasan pelanggan.

\section{Kaizen}

Menurut Cane (1998) dalam penelitian Arief Fatkhurrohman dan Sumbawa (2016) menjelaskan dalam bahasa Jepang, Kaizen berarti perbaikan yang berkesinambungan (continuous improvement). Ciri kunci manajemen kaizen antara lain yaitu lebih memperhatikan proses dan bukan hasil, manajemen fungsional silang dan menggunakan lingkaran kualitas dan peralatan lain untuk mendukung peningkatan yang terus menerus.

Konsep Kaizen menurut Misaki Imai dalam Roby Rio Andiwibowo, Joko Susetyo, dan Petrus Wisnubroto (2016), kaizen merupakan sebuah sistem perbaikan terus menerus pada kualitas, teknologi, proses, budaya perusahaan, produktivitas, keamanan, dan kepemimpinan. Istilah kaizen berasal dari bahasa Jepang yang artinya perbaikan berkelanjutan. Kai berarti perubahan dan zen berarti baik.

\section{Konsep PDCA}

Plan Do Check Action merupakan suatu metode yang dipopulerkan oleh Edward Deming dalam melakukan suatu proses perbaikan secara terus menerus. Pada gambar 1, siklus PDCA diibaratkan seperti sebuah roda yang harus terus didorong sehingga dapat mencapai tujuan yang telah dibuat dalam kerangka sistem perbaikan terus menerus agar terus naik.

Siklus PDCA dapat digunakan secara efektif dalam mengelola pekerjaan. Dalam siklus ini sangat memungkinkan untuk dapat melakukan dua jenis tindakan perbaikan yaitu perbaikan yang bersifat sementara dan permanen. Tidakan sementara untuk bertujuan mengatasi dan memperbaiki masalah secara praktis. Sedangkan tindakan perbaikan permanen, yang terdiri dari analisis dan menghilangkan akar penyebab untuk mencapai target proses perbaikan terus menerus (Sokovic, Pavlevic, Pipan, 2010). 
Konsep 7 Tools

Total Quality Management secara statistik dengan menggunakan Statistical Process Control (SPC) dan Statistical Quality Control (SQC) mempunyai 7 alat statistik utama yang dapat digunakan sebagai alat bantu untuk mengendalikan kualitas yang disebut sebagai 7 tools (Heizer dan Render, 2006), antara lain yaitu : diagram pareto, check sheet, scatter diagram,histogram, control chart, diagram sebab akibat, dan diagram proses.

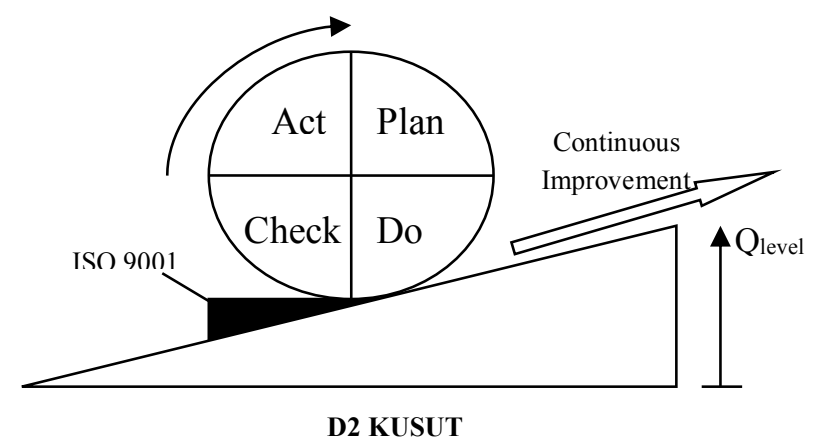

Gambar 1.Siklus PDCA dalam perbaikan terus menerus Sumber:Sokovic,M.,Pavlevic,D.,Pipan,K (2010)

\section{METODE PENELITIAN}

Tujuan dari QCC ini antara lain adalah sebagai berikut :
a. Mengurangi kesalahan-kesalahan dan meningkatkan kualitas.
b. Menggalang kerja sama tim yang lebih efektif.
c. Meningkatkan motivasi karyawan.
d. Meningkatkan keterlibatan dalam pekerjaan.
e. Meningkatkan keterampilan memecahkan masalah.
f. Menanamkan kesadaran dalam pencegahan masalah.
g. Meningkatkan efektifitas komunikasi dalam kelompok organisasi.
h. Menciptakan hubungan harmonis antara atasan dengan bawahan
i. Meningkatkan leadership.
j. Menciptakan kesadaran dalam menjaga keselamatan kerja.
k. Meningkatkan pengurangan biaya.

\section{Metode Analisis Data}

Metode analisis data pada penelitian ini menggunakan metode Metode Quality Control Circle.Menurut Vincent (2011) dalam penelitian Wahyu Rianto (2015) menerangkan bahwa Quality Control
Circle $(Q C C)$ adalah sekelompok kecil pekerja atau karyawan yang mempunyai pekerjaan yang sama atau sejenis, mengadakan pertemuan untuk membahas dan menyelesaikan masalah-masalah dalam perbaikan mutu dan biaya-biaya produksi dengan suka rela secara teratur dan berkesinambungan.

Menurut Sistem PT Toyota Astra Honda dalam penelitian Udi Gunawan (2017), menerangkan bahwa 8 langkah dalam pelaksanaan kegiatan QCC dengan langkah sebagai berikut :

1. Menentukan Tema

2. Menentukan Target

3. Aanalisa Kondisi Yang Ada

4. Analisa Sebab Akibat

5. Rencana Penanggulangan

6. Penanggulangan

7. Evaluasi Hasil

8. Standarisasi dan Tidak Lanjut

Untuk memudahkan dalam pemilihan alat yang akan digunakan dalam membantu dalam setiap tahapan perbaikan dengan menggunakan metode Quality Control Circle dan 7 tools, maka dapat dijelaskan dalam tabel 1. 
Tabel 1. Kombinasi Metode QCC dan 7 Tools

\begin{tabular}{|c|l|l|c|}
\hline Step & \multicolumn{1}{|c|}{ Aktifitas } & \multicolumn{1}{|c|}{ Alat/Teknik } & PDCA \\
\hline 1 & Menentukan Tema & $\begin{array}{l}\text { Lembar Pengumpulan Data, Diagram } \\
\text { Pareto, Histogram }\end{array}$ & Plan \\
\hline 2 & Menentukan Target & Histogram, Line Graph & Plan \\
\hline 3 & Analisa Kondisi yang Ada & \multicolumn{1}{|c|}{ Plan } \\
\hline 4 & Analisa Sebab Akibat & $\begin{array}{l}\text { Pareto Diagram, Fish Bone Diagram, } \\
\text { Why-Why Analysis }\end{array}$ & Plan \\
\hline 5 & Rencana Penanggulangan & $5 \mathrm{~W}+1 \mathrm{H}$ & Plan \\
\hline 6 & Pelaksanaan Penanggulangan & \multicolumn{1}{c}{-} & Do \\
\hline 7 & Evaluasi Hasil & $\begin{array}{l}\text { Lembar Pengumpulan Data, Diagram } \\
\text { Pareto, Histogram }\end{array}$ & Check \\
\hline 8 & Standarisasi dan Tindak Lanjut & \multicolumn{1}{c}{ - } & Action \\
\hline
\end{tabular}

Sumber: Buku Pedoman AstraTotal Quality Control (ATQC), Jakarta: PT Astra International

\section{HASIL DAN PEMBAHASAN}

Berdasarkan metode QCC yang sudah dilaksanakan oleh kelompok yang dibentuk dari orang-orang yang berasal Departemen D menggunakan konsep PDCAdan 7 tools. Kegiatan ini dilaksanakan dari bulan Desember 2018 sampai Maret 2019. Kegiatan ini bertujuan untuk mengidentifikasi segala permasalahan dan kendala yang ada pada Departemen D yang dimana data-data tersebut diambil dari datarekapitulasiproduktivitas selama tiga bulan terakhir.

Adapun analisis dari metode QCC menggunakam konsep PDCAdan 7 tools, yang akan dijelaskan sebagai berikut ini.

\section{Menentukan Tema}

Pada step pertama, kelompok QCC mengidentifikasi permasalahan dan kendala yang terjadi. Permasalahan tersebut bisa dipengaruhi dari beberapa faktor diantaranya faktor QCDSMP (Quality, Cost, Delivery/Delay, Safety, Morality, dan Productivity). Berikut data produktivitas yang berdasarkan faktor QCDSMP pada gambar 2 sampai dengan gambar 7.
Berdasarkan identifikasi dari grafik pengaruh QCDSMP (Quality, Cost, Delivery/Delay, Safety, Morality, dan Productivity) yang merupakan faktor dari permasalahan yang ada di Departemen D, yang paling menonjol dan tidak mencapai target adalah Grafik Quality. Kelompok QCC sepakat bahwa kegiatan ini dilakukan untuk memperbaiki Kualitas.

Setelah mengidentifikasi faktor permasalahan maka selanjutnya adalah mencari jenis-jenis permasalahan secara rinci, yang dimana jenis-jenis permasalahan tersebut merupakan jenisjenis cacat yang dihasilkan dari Departemen D sehingga berdampak pada menurunnya produktivitas dan kualitas kinerja Departemen D. tabel 2 menunjukkan rekapitulasi data cacat dari tiga bulan terakhir periode bulan September 2018 sampai dengan bulan November 2018.

Dari identifikasi data jenis cacat diatas, dapat ditarik kesimpulan bahwa jenis cacat D2 (Kusut) paling besar. Selanjutnya adalah membagi jenis cacat tersebut ke dalam jenis produk yang mengalami kendala. Berikut adalah data jenis produk yang mengalami cacat D2 (Kusut) yang ditunjukkan pada tabel 3. 


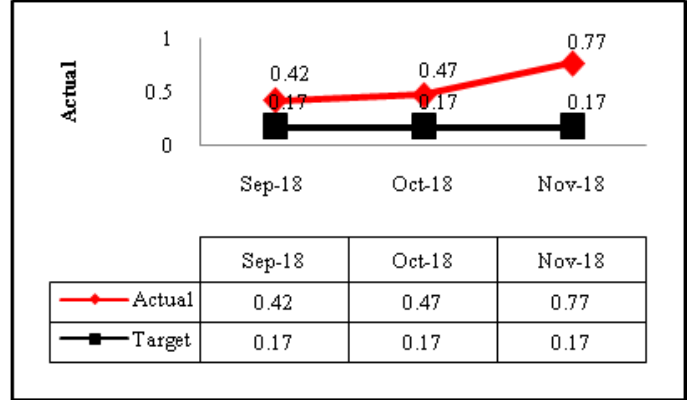

Gambar 2. Grafik Pengaruh Quality

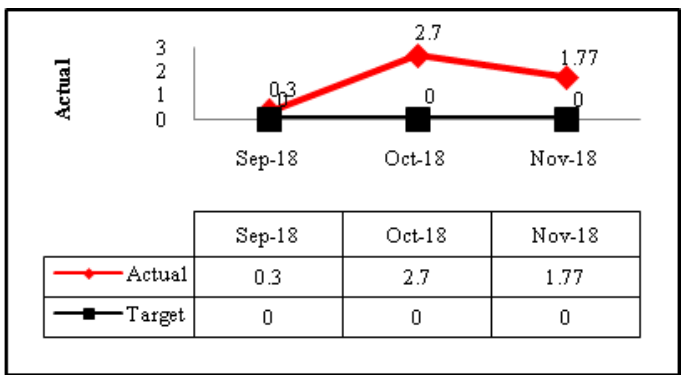

Gambar 4. Grafik Pengaruh Delivery/Delay

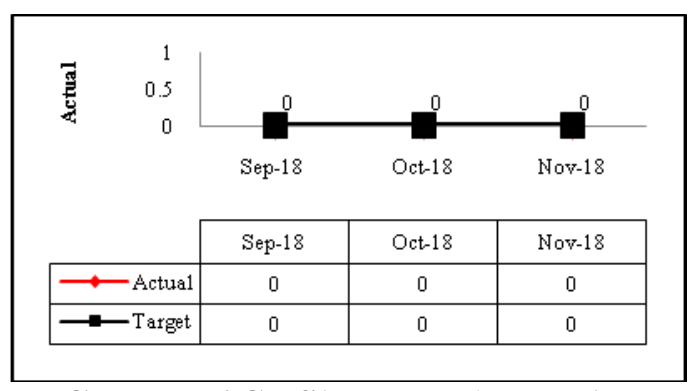

Gambar 6.Grafik Pengaruh Morality

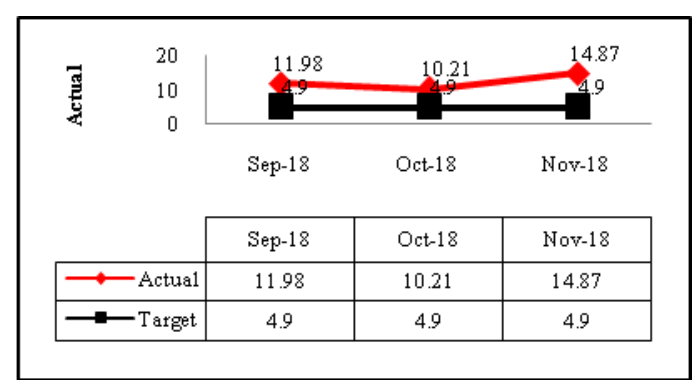

Gambar 3. Grafik Pengaruh Cost

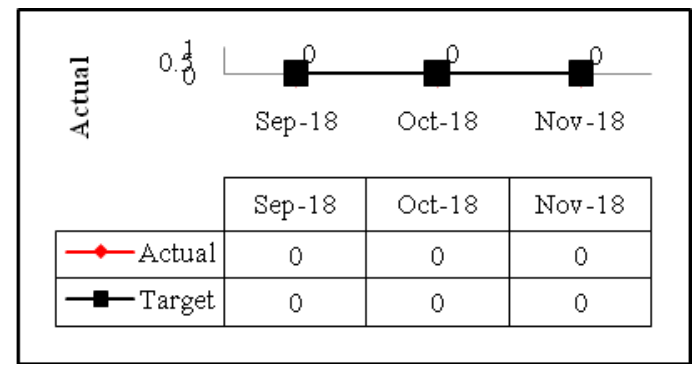

Gambar 5.Grafik Pengaruh Safety

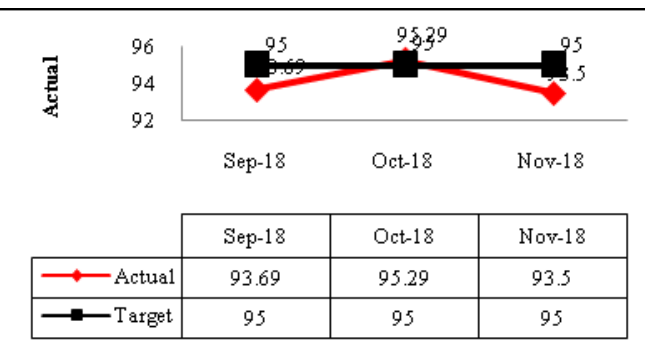

Gambar 7.Grafik Pengaruh Productivity

Tabel 2 Data Cacat, Periode Sep-18 s/d Nov-18

\begin{tabular}{|c|c|c|c|c|c|}
\hline \multirow{2}{*}{ No } & \multirow{2}{*}{$\begin{array}{c}\text { Jenis Cacat } \\
\text { Departemen D }\end{array}$} & \multicolumn{3}{|c|}{ BULAN } & \multirow{2}{*}{$\begin{array}{c}\text { Jumlah } \\
\text { Cacat }\end{array}$} \\
\hline & & Sep-18 & Okt-18 & Nov-18 & \\
\hline 1 & D1 (Warna NG) & 265 & 922,5 & 32 & 1219,5 \\
\hline 2 & D2 (Kusut) & 589,87 & 430,08 & 997,45 & 2017,4 \\
\hline 3 & D5 (Bolong) & 0 & 0,7 & 943,5 & 944,2 \\
\hline 4 & D4 (Kotor) & 282,82 & 199,48 & 112,31 & 594,61 \\
\hline 5 & D3 (Flek-flek) & 319,94 & 21,25 & 137,17 & 475,36 \\
\hline 6 & Trombol & 0 & 0 & 244,04 & 244,04 \\
\hline 7 & Aging & 26,2 & 90 & 16 & 132,2 \\
\hline 8 & $\begin{array}{l}\text { D6 (Bintik } \\
\text { Obat) }\end{array}$ & 45,72 & 15,02 & 10,2 & 70,94 \\
\hline 9 & $\begin{array}{l}\text { D8 (Ompol- } \\
\text { ompol) }\end{array}$ & 0 & 12 & 9,5 & 21,5 \\
\hline & 1529,55 & 1691,03 & 2502,17 & \\
\hline \multicolumn{2}{|r|}{ Pengiriman } & 362111,48 & 362620,683 & 323118,767 & \\
\hline \multicolumn{2}{|r|}{ Presentase } & 0,42 & 0,47 & 0,77 & \\
\hline
\end{tabular}


Tabel 3.Data Cacat D2 pada Jenis Produk, Periode Sep-18 s/d Nov-18

\begin{tabular}{|l|r|c|r|r|r|r|}
\hline \multirow{2}{*}{ Jenis Produk } & \multicolumn{7}{|c|}{ BULAN } \\
\cline { 2 - 7 } & Sep-18 & \% & Okt-18 & \% & \multicolumn{1}{c|}{ Nov-18 } & \% \\
\hline$T I$ & 308,64 & 0,09 & 43,92 & 0,01 & 85 & 0,03 \\
\hline$H F$ & 281,23 & $\mathbf{0 , 0 8}$ & 386,16 & $\mathbf{0 , 1 1}$ & 912,45 & $\mathbf{0 , 2 8}$ \\
\hline Total & 589,87 & 0,17 & 430,08 & 0,12 & 997,45 & 0,31 \\
\hline Pengiriman (Meter) & 362111,48 & & 362620,683 & & 323118,767 & \\
\hline
\end{tabular}

Dari identifikasi data yang ditunjukkan tabel 3, jenis produk yang mengalami cacat D2 (Kusut), bahwa yang paling banyak mengalami cacat D2 adalah jenis produk $H F$.

Langkah selanjutnya adalah mengidentifikasi lebih spesifik jenis-jenis desain apa saja yang mengalami cacat D2 (Kusut) pada produk $H F$. Tabel 4 berikut ini adalah data jenis-jenis desain dari produk $H F$ yang mengalami cacat $\mathrm{D} 2$ (Kusut).

Berdasarkan

identifikasiidentifikasi dari data pada tabel 4 dan gambar 8 tersebut, kelompok QCC sepakat bahwa tema yang diambil adalah "Menurunkan Cacat D2 (Kusut)Produk HF Pada Desain NL". Tabel 5 menunjukkan persentase dari data cacat $\mathrm{D} 2$ pada produk HP dsain NL pada periode September sampai dengan 18 november

\section{Menentukan Target}

Selanjutnya pada step kedua adalah menentukan target dimana target ini sebagai perencanaan pelaksanaan setelah dilakukannya QCC. Berikut adalah grafik perencanaan target menurunkan cacat D2 (Kusut) produk Home Furnishing pada desain NL.

Berdasarkan grafik pada gambar 9 maka telah ditetapkan bahwa kelompok QCC menetapkan target penurunan yang akan berakhir pada bulan April 2019 hingga mencapai $0,06 \%$. Adapun alasan penetapan target berdasarkan poin-poin SMART adalah sebagai berikut :

1. Spesific : Menurunkan cacat D2 (Kusut) produk Home Furnishing pada desain NL.

2. Measurable: Menurunkan cacat dari rata-rata $0,1 \%$ menjadi $0,06 \%$ sesuai dengan pencapaian terbaik.

3. Achievable: Target ditetapkan sesuai pencapaian aktual di bulan September 2018.

4. Reasonable : Target ditetapkan dengan aktivitas yang jelas dan bertahap.

Tabel 4.Data Cacat D2 Terhadap Desain Produk $H F$, Periode Sep-18 s/d Nov-18

\begin{tabular}{|c|c|c|c|c|c|c|}
\hline \multirow{2}{*}{ Desain } & \multicolumn{3}{|c|}{ BULAN } & \multirow[t]{2}{*}{ Rata-rata } & \multirow[t]{2}{*}{$\%$} & \multirow[t]{2}{*}{$\begin{array}{c}\% \\
\text { Kum } \\
\end{array}$} \\
\hline & Sep-18 & Okt-18 & Nov-18 & & & \\
\hline $\mathrm{NL}$ & 236,43 & 357,54 & 409,94 & $\mathbf{3 3 1 , 3 0}$ & 62,79 & 62,79 \\
\hline NP & 0 & 0 & 308 & 102,67 & 19,46 & 82,25 \\
\hline DF & 0 & 0 & 109,60 & 36,53 & 6,92 & 89,18 \\
\hline $\mathrm{CO}$ & 0 & 29 & 47,66 & 25,55 & 4,84 & 94,02 \\
\hline FL & 29,3 & 0 & 12 & 13,77 & 2,61 & 96,63 \\
\hline $\mathrm{AS}$ & 25,5 & 0 & 0 & 8,5 & 1,62 & 98,24 \\
\hline PR & 0 & 0 & 22,5 & 7,5 & 1,42 & 99,66 \\
\hline KT & 0 & 2,62 & 2,75 & 1,79 & 0,34 & 100 \\
\hline & & & Total & 527,61 & 100 & \\
\hline
\end{tabular}




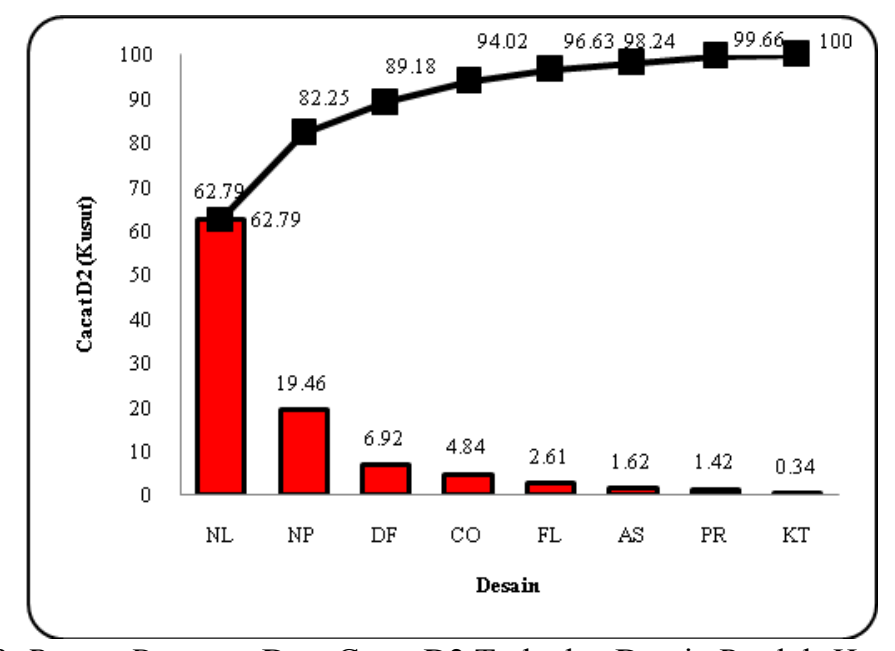

Gambar 8. Pareto Diagram Data Cacat D2 Terhadap Desain Produk Home Furnishing

Tabel 5. Data Cacat D2 pada Produk HF Desain NL, Periode Sep-18 s/d Nov-18

\begin{tabular}{|l|r|r|r|r|}
\hline \multirow{2}{*}{ Desain } & \multicolumn{3}{|c|}{ BULAN } & \multirow{2}{*}{ Rata-rata } \\
\cline { 2 - 4 } & \multicolumn{1}{|c|}{ Sep-18 } & \multicolumn{1}{c|}{ Okt-18 } & \multicolumn{1}{c|}{ Nov-18 } & \\
\hline NL & 236,43 & 357,54 & 409,94 & 331,3 \\
\hline Pengiriman (Meter) & 362111,48 & 362620,683 & 323118,767 & 349263,6 \\
\hline$\%$ & 0,06 & 0,1 & 0,13 & $\mathbf{0 , 1}$ \\
\hline
\end{tabular}

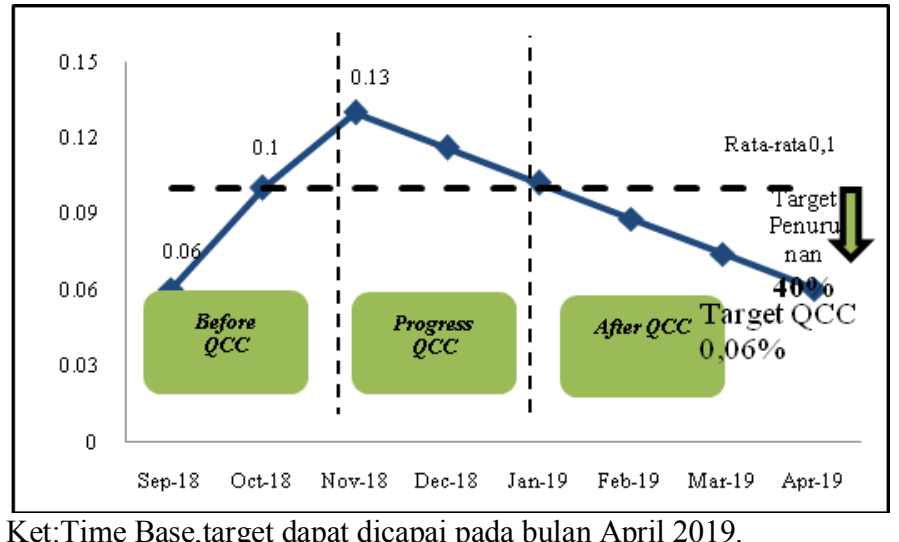

Gambar 9.Penurunan Target Cacat D2 Terhadap Desain NL pada Produk Home Furnishing

\section{Analisa Kondisi Yang Ada}

Dari step ini dapat diperoleh berbagai data aktual dan faktor-faktor yang mempengaruhi mengenai terjadinya cacat D2. Adapun faktor-faktor tersebut yang masih dalam tahap perkiraan, diantaranya adalah sebagai berikut :

1. Man : Cacat D2 bisa saja terjadi diakibatkan sambungan hasil jahitan operator membuat kondisi kain mengkerut; Bisa saja dari saat pemotongan sample operator belum memiliki keahlian khusus.

2. Method :Handling dilakukan pada roda gantung sesuai prosedur tetapi masih ada lipatan; Proses persiapan dilakukan pada mesin persiapan dan tidak dibeber di roda kotak.

3. Material : Kondisi kain greige pada proses sebelumnya masih tidak rapih dan terdapat banyak lipatan; Level air mesin Dyeing tidak sesuai dengan kebutuhan. 
4. Machine : Sirkulasi pada saat proses di mesin Dyeing abnormal sehingga menyebabkan penumpukkan di dalam mesin.

5. Environment : Suhu dan kelembaban tidak sesuai dengan standar produksi.

\section{Analisa Sebab Akibat}

Pada step ini dilakukan pengamatan langsung di lapangan terkait terjadi kendala yang diakibatkan dari beberapa faktor yang telah dijelaskan pada step sebelumnya. Analisa sebab akibat dapat digambarkan menggunakan Fish Bone Diagram atau Diagram Tulang Ikan. Berikut adalah gambaran Fish Bone Diagram dari analisa sebab akibat pada gambar 10.

Adapun data hasil di lapangan yang menunjukkan pengaruh besar terjadinya cacat D2 pada produk Home Furnishing desain NL ada tabel 5 berikut.

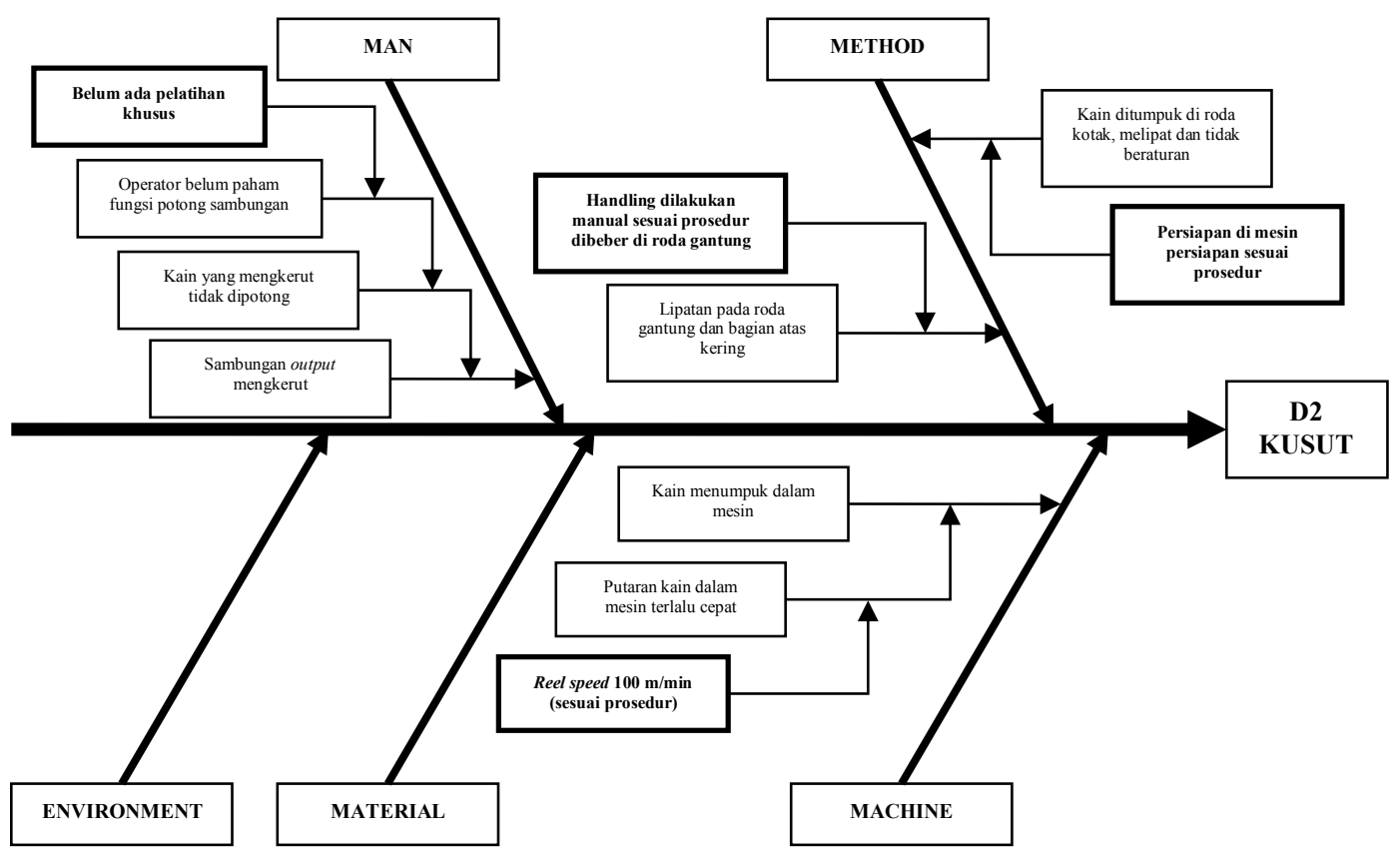

Gambar 10. Fish Bone Diagram Analisis Sebab Akibat dari Cacat D2 Terhadap Desain NL pada Produk Home Furnishing

Tabel 5.Laporan Data Hasil di Lapangan Mengenai Cacat D2 pada Produk Home Furnishing Desain NL

\begin{tabular}{|c|c|l|c|c|c|c|c|}
\hline No & Faktor & \multicolumn{1}{|c|}{ Penyebab } & $\begin{array}{c}\text { Frekuensi } \\
\text { Percobaan }\end{array}$ & $\%$ & \% Kum & $\begin{array}{c}\text { Sumbangsih } \\
\text { Cacat }\end{array}$ & $\begin{array}{c}\text { Target } \\
\text { Turun }\end{array}$ \\
\hline 1 & Method & $\begin{array}{l}\text { Handling dilakukan di roda } \\
\text { gantung sesuai standar tapi } \\
\text { masih ada lipatan. }\end{array}$ & 7 & 53,85 & 53,85 & 0,11 & 0,066 \\
\hline 2 & Machine & $\begin{array}{l}\text { Reel speed } 100 \mathrm{~m} / \mathrm{min} \\
\text { sesuai dengan standar tapi } \\
\text { kain masih terjadi } \\
\text { penumpukkan di dalam } \\
\text { mesin. }\end{array}$ & 3 & 23,06 & 76,923 & 0,05 & 0,03 \\
\hline 3 & Method & $\begin{array}{l}\text { Proses persiapan kain } \\
\text { dilakukan di mesin } \\
\text { persiapan dan tidak dibeber } \\
\text { pada roda kotak. }\end{array}$ & 2 & 15,38 & 92,308 & 0,03 & 0,018 \\
\hline & Man & $\begin{array}{l}\text { Operator belum ada } \\
\text { pelatihan khusus } \\
\text { pemotongan kain } \text { output. }\end{array}$ & 1 & 7,69 & 100 & 0,01 & 0,006 \\
\hline
\end{tabular}




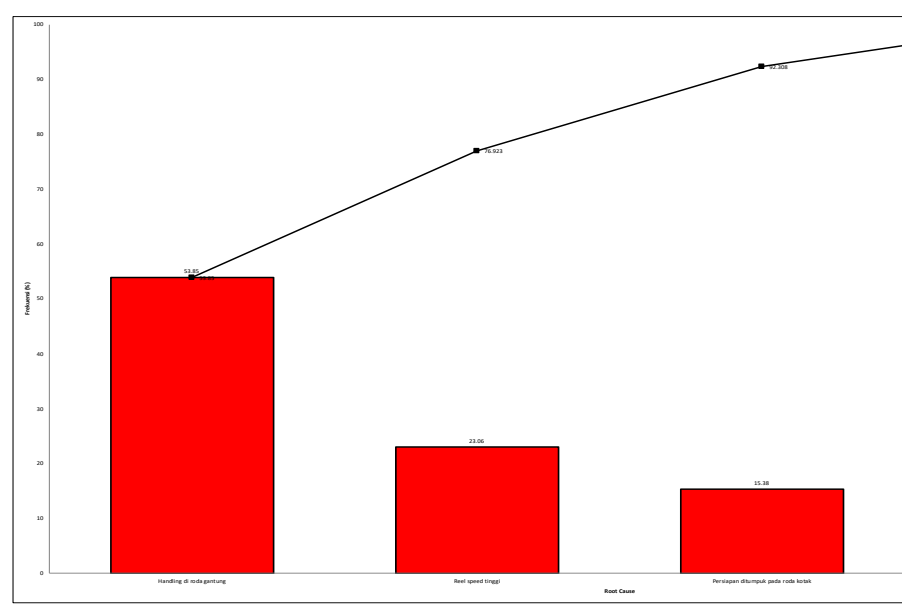

Gambar 11. Pareto Diagram dari Laporan Data Hasil di Lapangan Mengenai Cacat D2 pada Produk Home Furnishing Desain NL

Tabel 6 Rencana Penanggulangan Cacat D2 pada Produk Home Furnishing Desain NL

\begin{tabular}{|c|c|c|c|c|c|c|c|}
\hline \multirow[b]{2}{*}{ Faktor } & \multicolumn{2}{|c|}{ What } & \multirow{2}{*}{$\begin{array}{c}\text { Why } \\
\text { Alasan }\end{array}$} & \multirow{2}{*}{$\begin{array}{c}\text { How } \\
\text { Detil } \\
\text { Aktivitas }\end{array}$} & \multirow{2}{*}{$\begin{array}{l}\text { Where } \\
\text { Lokasi }\end{array}$} & \multirow{2}{*}{$\begin{array}{l}\text { When } \\
\text { Kapan }\end{array}$} & \multirow{2}{*}{$\begin{array}{l}\text { Who } \\
\text { PIC }\end{array}$} \\
\hline & Penyebab & Solusi & & & & & \\
\hline Method & $\begin{array}{l}\text { Handling } \\
\text { dilakukan } \\
\text { manual } \\
\text { sesuai } \\
\text { prosedur } \\
\text { dibeber di } \\
\text { roda } \\
\text { gantung. }\end{array}$ & $\begin{array}{l}\text { Handling } \\
\text { manual } \\
\text { dibeber di } \\
\text { roda fiber } \\
\text { kotak, } \\
\text { atasnya } \\
\text { ditutup } \\
\text { plastik. }\end{array}$ & $\begin{array}{l}\text { Agar kain bisa } \\
\text { lebih rapih dan } \\
\text { tetap } \\
\text { basah/lembab. }\end{array}$ & $\begin{array}{l}\text { Kain } \\
\text { dibeber } \\
\text { manual oleh } \\
2 \text { orang } \\
\text { operator } \\
\text { dengan } \\
\text { rapih. }\end{array}$ & $\begin{array}{l}\text { Mesin } \\
\text { Dyeing }\end{array}$ & $\begin{array}{l}1 \mathrm{Jan}- \\
19 \mathrm{~s} / \mathrm{d} \\
5 \mathrm{Jan}- \\
19\end{array}$ & $\begin{array}{l}\text { Operator } \\
\text { Produksi }\end{array}$ \\
\hline Machine & $\begin{array}{l}\text { Reel } \\
\text { speed } 100 \\
\mathrm{~m} / \mathrm{min} \\
\text { sesuai } \\
\text { dengan } \\
\text { prosedur }\end{array}$ & $\begin{array}{l}\text { Penyesuaian } \\
\text { reel speed } \\
\text { dari } 100 \\
\text { m/min } \\
\text { menjadi } 90 \\
\text { m/min. }\end{array}$ & $\begin{array}{l}\text { Mengurangi } \\
\text { penumpukkan } \\
\text { di dalam mesin } \\
\text { saat proses } \\
\text { pencelupan. }\end{array}$ & $\begin{array}{l}\text { Melakukan } \\
\text { trial } \\
\text { pengamatan } \\
\text { dan } \\
\text { penyetingan } \\
\text { mesin. }\end{array}$ & $\begin{array}{l}\text { Mesin } \\
\text { Dyeing }\end{array}$ & $\begin{array}{l}1 \mathrm{Jan}- \\
19 \mathrm{~s} / \mathrm{d} \\
5 \mathrm{Jan}- \\
19\end{array}$ & $\begin{array}{l}\text { Operator } \\
\text { Produksi }\end{array}$ \\
\hline Method & $\begin{array}{l}\text { Persiapan } \\
\text { kain } \\
\text { dilakukan } \\
\text { di mesin } \\
\text { persiapan. }\end{array}$ & $\begin{array}{l}\text { Persiapan } \\
\text { kain } \\
\text { dibeber di } \\
\text { roda } \\
\text { gantung. }\end{array}$ & $\begin{array}{l}\text { Menghilangkan } \\
\text { proses } \\
\text { penumpukkan } \\
\text { kain di roda } \\
\text { kotak dan } \\
\text { meminimalisir } \\
\text { lipatan di roda } \\
\text { kotak. } \\
\end{array}$ & $\begin{array}{l}\text { Menyiapkan } \\
\text { roda } \\
\text { gantung dan } \\
\text { dibeber oleh } \\
2 \text { orang } \\
\text { operator } \\
\text { dengan } \\
\text { rapih. }\end{array}$ & $\begin{array}{l}\text { Mesin } \\
\text { Persiapan }\end{array}$ & $\begin{array}{l}1 \mathrm{Jan}- \\
19 \mathrm{~s} / \mathrm{d} \\
5 \mathrm{Jan}- \\
19\end{array}$ & $\begin{array}{l}\text { Operator } \\
\text { Persiapan }\end{array}$ \\
\hline Man & $\begin{array}{l}\text { Belum } \\
\text { ada } \\
\text { pelatihan } \\
\text { khusus } \\
\text { mengenai } \\
\text { fungsi } \\
\text { dan cara } \\
\text { kerja } \\
\text { potong } \\
\text { kain saat } \\
\text { output. }\end{array}$ & $\begin{array}{l}\text { Pelatiahan } \\
\text { untuk } \\
\text { operator } \\
\text { produksi } \\
\text { mesin } \\
\text { Dyeing. }\end{array}$ & $\begin{array}{l}\text { Agar operator } \\
\text { mengerti } \\
\text { kualitas. }\end{array}$ & $\begin{array}{l}\text { Menyiapkan } \\
\text { materi } \\
\text { pelatihan } \\
\text { yang akan } \\
\text { diberikan } \\
\text { kepada } \\
\text { operator. }\end{array}$ & $\begin{array}{l}\text { Mesin } \\
\text { Dyeing }\end{array}$ & $\begin{array}{l}1 \mathrm{Jan}- \\
19 \mathrm{~s} / \mathrm{d} \\
5 \mathrm{Jan}- \\
19\end{array}$ & $\begin{array}{l}\text { Staf } \\
\text { Departemen } \\
\text { Dyeing }\end{array}$ \\
\hline
\end{tabular}




\section{Rencana Penanggulangan}

Setelah mengetahui akar-akar permasalahannya, maka pada step selanjutnya adalah menyusun suatu perencanaan penanggulangan yang dibuat un menggunakan konsep $5 \mathrm{~W}+1 \mathrm{H}$ ditunjukkan pada tabel 6 .

\section{Penanggulangan}

Setelah membuat perencanaan dalam hal penanggulangan, langkah selanjutnya adalah pelaksanaan secara jelas agar dapat dengan mudah dipahami oleh setiap anggota kelompok QCC. Adapun rencana penanggulangan tersebut disus

penanggulangan. Dalam pelaksanaan penanggulangan ini, semua yang terlibat menjalankan apa yang sudah direncanakan pada step sebelumnya. Adapun hasil laporan penanggulangan yang telah dilaksanakan adalah sebagai berikut :

1. Handling dilakukan di roda gantung sesuai dengan standar kerja, ada lipatan.

Tabel 7 Penanggulangan Pertama Faktor Method

\begin{tabular}{|c|c|c|c|c|c|c|}
\hline \multirow{2}{*}{ Penanggulangan } & \multicolumn{2}{|c|}{ Detail Penanggulangan } & \multirow{2}{*}{ Lokasi } & \multirow{2}{*}{$\begin{array}{c}\text { Tanggal } \\
\text { Pelaksanaan }\end{array}$} & \multirow{2}{*}{ PIC } & \multirow{2}{*}{ Hasil } \\
\hline & Aktivitas & Realisasi & & & & \\
\hline $\begin{array}{l}\text { Handling manual } \\
\text { dibeber di roda } \\
\text { fiber kotak dan } \\
\text { atasnya ditutup } \\
\text { plastik. }\end{array}$ & $\begin{array}{l}\text { Mengganti } \\
\text { standar } \\
\text { kerja lama } \\
\text { dengan } \\
\text { standar } \\
\text { kerja } \\
\text { temporari. }\end{array}$ & $\begin{array}{l}\text { Menganalisis } \\
\text { lipatan kain } \\
\text { pada roda } \\
\text { fiber kotak. }\end{array}$ & $\begin{array}{l}\text { Mesin } \\
\text { Dyeing }\end{array}$ & $\begin{array}{l}10 \text { Jan-19 s/d } \\
15 \text { Jan-19 }\end{array}$ & $\begin{array}{l}\text { Operator } \\
\text { Produksi }\end{array}$ & $\begin{array}{c}\text { TIDAK } \\
\text { BERHASIL }\end{array}$ \\
\hline $\begin{array}{l}\text { (Melakukan } \\
\text { PDCA) } \\
\text { Handling manual } \\
\text { dibeber di roda } \\
\text { fiber kotak dan } \\
\text { diberi rendam } \\
\text { air. }\end{array}$ & $\begin{array}{l}\text { Melakukan } \\
\text { simulasi } \\
\text { trial. }\end{array}$ & $\begin{array}{l}\text { Menganalisis } \\
\text { lipatan kain } \\
\text { pada roda } \\
\text { fiber kotak. }\end{array}$ & $\begin{array}{l}\text { Mesin } \\
\text { Dyeing }\end{array}$ & $\begin{array}{l}20 \text { Jan-19 s/d } \\
22 \text { Jan-19 }\end{array}$ & $\begin{array}{l}\text { Operator } \\
\text { Produksi }\end{array}$ & BERHASIL \\
\hline
\end{tabular}

2. Reel speed sesuai standar $100 \mathrm{~m} / \mathrm{min}$ dan cycle time $90 \mathrm{~m} / \mathrm{min}$ tapi masih menumpuk di dalam mesin.

Tabel 8 Penanggulangan Kedua Faktor Machine

\begin{tabular}{|c|c|c|c|c|c|c|}
\hline \multirow{2}{*}{ Penanggulangan } & \multicolumn{2}{|c|}{ Detail Penanggulangan } & \multirow{2}{*}{ Lokasi } & \multirow{2}{*}{$\begin{array}{c}\text { Tanggal } \\
\text { Pelaksanaan }\end{array}$} & \multirow{2}{*}{ PIC } & \multirow{2}{*}{ Hasil } \\
\hline & Aktivitas & Realisasi & & & & \\
\hline $\begin{array}{l}\text { Penyesuaian reel } \\
\text { speed dari } \\
\text { standar } 100 \\
\mathrm{~m} / \mathrm{min} \text { menjadi } \\
90 \mathrm{~m} / \mathrm{min} .\end{array}$ & $\begin{array}{l}\text { Trial } \\
\text { pengamatan } \\
\text { reel speed } \\
\text { pada mesin, } \\
\text { cek } \\
\text { sirkulasi } \\
\text { kain di } \\
\text { dalam } \\
\text { mesin. }\end{array}$ & $\begin{array}{l}\text { Menganalisis } \\
\text { tumpukkan } \\
\text { kain di } \\
\text { dalam mesin. }\end{array}$ & $\begin{array}{l}\text { Mesin } \\
\text { Dyeing }\end{array}$ & $\begin{array}{l}10 \mathrm{Jan}-19 \mathrm{~s} / \mathrm{d} \\
15 \mathrm{Jan}-19\end{array}$ & $\begin{array}{l}\text { Operator } \\
\text { Produksi }\end{array}$ & BERHASIL \\
\hline
\end{tabular}


3. Proses persiapan kain dilakukan tidak dibeber pada roda kotak.

Tabel 9 Penanggulangan Ketiga Faktor Method

\begin{tabular}{|c|c|c|c|c|c|c|}
\hline \multirow{2}{*}{ Penanggulangan } & \multicolumn{2}{|c|}{ Detail Penanggulangan } & \multirow{2}{*}{ Lokasi } & \multirow{2}{*}{$\begin{array}{c}\text { Tanggal } \\
\text { Pelaksanaan }\end{array}$} & \multirow{2}{*}{ PIC } & \multirow{2}{*}{ Hasil } \\
\hline & Aktivitas & Realisasi & & & & \\
\hline $\begin{array}{l}\text { Persiapan kain di } \\
\text { mesin persiapan } \\
\text { dibeber ke roda } \\
\text { gantung dengan } \\
\text { rapih. }\end{array}$ & $\begin{array}{l}\text { Menganalisis } \\
\text { perubahan } \\
\text { persiapan } \\
\text { dari roda } \\
\text { kotak ke } \\
\text { roda } \\
\text { gantung. }\end{array}$ & $\begin{array}{l}\text { Menganalisis } \\
\text { lipatan kain } \\
\text { pada roda } \\
\text { gantung. }\end{array}$ & $\begin{array}{l}\text { Mesin } \\
\text { Persiapan }\end{array}$ & $\begin{array}{l}10 \mathrm{Jan}-19 \mathrm{~s} / \mathrm{d} \\
15 \mathrm{Jan}-19\end{array}$ & $\begin{array}{l}\text { Operator } \\
\text { Persiapan }\end{array}$ & BERHASIL \\
\hline
\end{tabular}

4. Operator belum ada pelatihan khusus pemotongan sample pada saat output.

Tabel 10. Penanggulangan Keempat Faktor Man

\begin{tabular}{|c|c|c|c|c|c|c|}
\hline \multirow{2}{*}{ Penanggulangan } & \multicolumn{2}{|c|}{ Detail Penanggulangan } & \multirow{2}{*}{ Lokasi } & \multirow{2}{*}{$\begin{array}{c}\text { Tanggal } \\
\text { Pelaksanaan }\end{array}$} & \multirow{2}{*}{ PIC } & \multirow{2}{*}{ Hasil } \\
\hline & Aktivitas & Realisasi & & & & \\
\hline $\begin{array}{l}\text { Pelatihan } \\
\text { operator. }\end{array}$ & $\begin{array}{l}\text { Dibuatkan } \\
\text { bahan } \\
\text { pelatihan } \\
\text { untuk } \\
\text { operator. }\end{array}$ & $\begin{array}{l}\text { Memberikan } \\
\text { pelatihan } \\
\text { operator } \\
\text { tentang } \\
\text { kualitas. }\end{array}$ & $\begin{array}{l}\text { Mesin } \\
\text { Dyeing }\end{array}$ & $\begin{array}{l}10 \text { Jan-19 s/d } \\
15 \text { Jan-19 }\end{array}$ & $\begin{array}{l}\text { Staf } \\
\text { Departemen } \\
\text { Dyeing }\end{array}$ & BERHASIL \\
\hline
\end{tabular}

\section{Evaluasi Hasil}

Setelah

melakukan

penanggulangan, dilakukan evaluasi setiap periode baik sebelum pelaksanaan QCC maupun setelah pelaksanaan QCC. Adapun hasil evaluasi sebelum QCC sampai dengan sesudah QCC adalah ditunjukkan pada tabel 11 dan gambar 12 berikut.

Berdasarkan laporan dan grafik evaluasi hasil dari penanggulangan cacat D2 (Kusut) pada produk Home Furnishing desain NL, menunjukkan bahwa terjadi penurunan sebanyak $88,3 \%$ yang diambil dari data hasil di lapangan. Artinya, kelompok QCC telah berhasil menurunkan cacat D2 (Kusut) pada produk Home Furnishing desain NL.

\section{Standarisasi dan Tindak Lanjut}

Setelah melakukan evaluasi hasil, langkah selanjutnya adalah membuat standarisasi yang baru dan mengganti standarisasi yang lama. Tujuannya adalah agar tidak terjadi masalah dan kendala yang di kemudian hari. Standarisasi ini juga harus mendapatkan follow up atau persetujuan dari atasan-atasan Departeman D meliputi Group Head, Section Head, Supervisor, dan Manager.

Adapun standarisasi atau standar kerja yang baru dimana standar kerja ini adalah hasil dari pelaksanaan QCC mengenai menurunkan cacat D2 (Kusut) pada produk Home Furnishing desain NL ditujukkan pada gambar 13.

Setelah melakukan pelaksanaan Quality Control Circle, selanjutnya adalah melakukan analisis mengenai dampak dan keuntungan dari pelaksanaan QCC tersebut yang berpengaruh besar terhadap faktor QCDSMP (Quality, Cost, Delivery/Delay, Safety, Morality, dan Productivity). Adapun hasil laporan yang diperoleh mengenai analisis sebelum QCC dan setelah QCC serta keuntungan yang diperoleh dari pelaksanaan QCC tersebut adalah sebagai berikut :

\section{a) Quality}

Sebelum QCC : Kualitas yang dihasilkan menurun. Cacat rata-rata $0,64 \%$ tidak mencapai target yang dicanangkan perusahaan yaitu $0,17 \%$. 
Setelah QCC : Kualitas yang dihasilkan meningkat. Target cacat tercapai dari rata-rata $0,13 \%$.

Keuntungan : Cacat turun, target perusahaan tercapai untuk Departemen Dyeing.

b) Cost

Sebelum QCC : Cacat karena D2 (Kusut) adalah 0,64\% atau 2017,4 meter dari periode bulan September 2018 sampai November 2018.

Setelah QCC : Cacat dapat diturunkan menjadi rata-rata $0,13 \%$ atau 202,31 meter.

Penurunan cacat D2 (Kusut) : $\frac{2017,4 \text { meter }-202,31 \text { meter }}{2017,4 \text { meter }} \times 100 \%=90 \%$

Keuntungan : Cacat D2 (Kusut) dapat diturunkan dengan keuntungan yang diperoleh adalah :

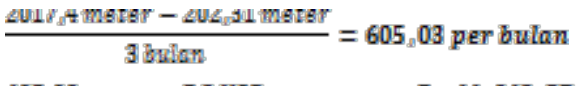

605,03 meter $\times$ 78 USD permater $=$ Rp.66.069.276

Asumsi 1 USD $=$ Rp.14,000

\section{c) Delivery/Delay}

Sebelum QCC : Pengiriman terhambat karena cacat D2 (Kusut). Produksi harus mengganti kain tambahan untuk pengganti produk yang cacat.

Setelah QCC : Pengiriman lebih cepat tanpa hambatan cacat.
Keuntungan :Delay nol, delivery on time.

d) Safety

Sebelum QCC : Potensi operator sakit pada tangan dan pinggang karena membeberkan kain ke roda gantung secara manual.

Setelah QCC : Potensi dapat diminimalisir, kecelakaan menurun karena mengikuti standar kerja. Cara membeber kain dibantu dengan reel speed pada mesin dyeing.

Keuntungan : Kecelakaan nol. Operator lebih safety dalam bekerja.

e) Morality

Sebelum QCC : Tidak ada peningkatan skill anggota.

Setelah QCC : Adanya peningkatan skill anggota.

Keuntungan : Dengan adanya peningkatan skill anggota, produktivitas dan kualitas meningkat.

\section{f) Productivity}

Sebelum QCC : Banyak perbaikan kualitas sehingga produktivitas menurun.

Setelah QCC : Produktivitas meningkat karena tidak ada produk yang cacat.

Keuntungan : Produktivitas meningkatkan yang berdampak pada insentif dan reward pun meningkat.

Tabel 11. Evaluasi Hasil dari Penanggulangan Cacat D2 pada Produk Home Furnishing Desain NL

\begin{tabular}{|c|c|c|c|c|c|c|c|c|}
\hline \multirow{2}{*}{ ITEM } & \multicolumn{8}{|c|}{ BULAN } \\
\hline & Sep-18 & Okt-18 & Nov-18 & Des-18 & Jan-19 & Feb-19 & Mar-19 & Apr-19 \\
\hline Pengiriman & 362111,48 & 362620,683 & 323118,767 & 243637,32 & 241978,32 & 256427,32 & 354429,3 & 350967,54 \\
\hline $\begin{array}{l}\text { Cacat D2 } \\
\text { desain NL } \\
\text { (m) }\end{array}$ & 226,43 & 357,54 & 409,94 & 221,45 & 187,2 & 37,34 & 14,1 & 21,5 \\
\hline$\%$ & 0,06 & 0,10 & 0,13 & 0,09 & 0,08 & 0,01 & 0,004 & 0,006 \\
\hline $\begin{array}{l}\text { \% Rata- } \\
\text { rata }\end{array}$ & & 0,10 & & & 09 & & 0,007 & \\
\hline $\begin{array}{l}\text { Target } \\
\text { QCC }\end{array}$ & & Sebelum QC & & Sedan & g QCC & & etelah QC & \\
\hline
\end{tabular}




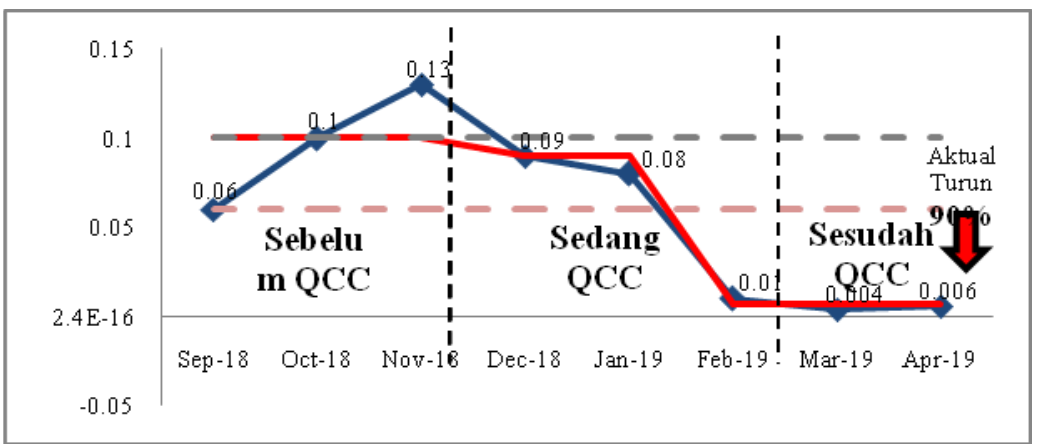

Gambar 12. Grafik Evaluasi Hasil dari Penanggulangan Cacat D2 pada Produk Home Furnishing Desain $\mathrm{NL}$

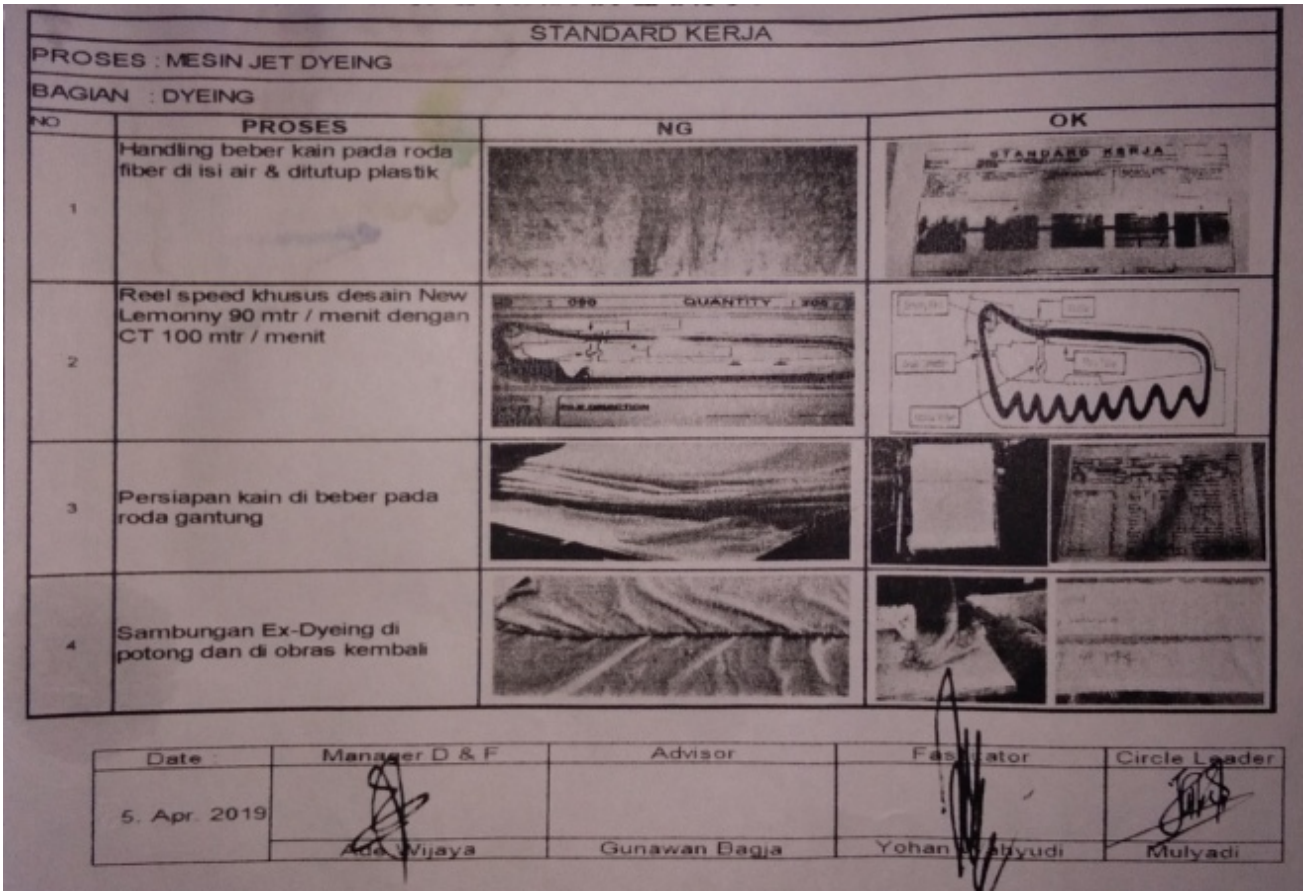

Gambar 13. Standar Kerja yang Baru pada Produk Home Furnishing Desain NL

\section{KESIMPULAN DAN SARAN}

\section{Kesimpulan}

Berdasarkan hasil laporan penelitian yang telah dilakukan dapat disimpulkan bahwa penerapan budaya kerja kaizen masih belum berjalan secara efektif padahal dampak terhadap produktivitas dan kinerja karyawan sangat berpengaruh. Salah satunya adalah keikutsertaan secara suka rela yang diikuti oleh karyawan atau orang-orang yang berasal dari Departemen D, hanya sebagian orang saja yang suka rela meluangkan waktu untuk berdiskusi mengenai pemecahan masalah dan kendala yang ada di Departemen D. Sebenarnya budaya kerja kaizen dipakai untuk mengatasi masalah-masalah ataupun kendala-kendala setiap karyawan di lingkungan kerja. Budaya kerja kaizen diterapkan di semua departemen dan bagian yang ada di PT X, termasuk di Departemen D. Budaya kerja kaizen ini bisa digunakan untuk menyelesaikan suatu permasalahan karena kaizen itu memang difungsikan untuk menyelesaikan suatu permasalahan, bagaimana mencari solusi yang lebih baik dan lebih cepat. Penerapan ISO 9001:2008 di PT X, khususnya di 
Departemen D, adalah mengurangi variasi dan pemborosan, serta melakukan kontrol terhadap semua proses, bahan dan alat yang digunakan dalam proses, salah satunya adalah melalui metode Quality Control Circle.

\section{Saran}

Berdasarkan hasil Quality Control Circle yang telah dilaksanakan bahwa Departemen D telah melakukan perbaikan pada kualitas sehingga dapat berdampak positif pada kinerja dan produktivitas. Selain itu, konsep Quality Control Circle ini pula sering dilakukan pada setiap periode tertentu atau jika terjadi suatu permasalahan pada lingkungan kerja Departemen D seperti ketentuan dan peraturan (Standar Operasional Procedure) dari perusahaan. Pada hakikatnya konsep Quality Control Circle merupakan salah satu dari budaya kerja kaizen. Oleh sebab itu, Departemen D perlu mempertahankan atau menerapkan budaya kerja kaizen di lingkungan kerja walaupun masih belum optimal dan hanya sebagian orang yang suka rela ikut serta melakukan budaya kerja kaizen.

\section{DAFTAR PUSTAKA}

Andiwibowo, Roby Rio, Susetyo, Andi dan Wisnubroto, Petrus. 2018. Pengendalian Kualitas Produk Kayu Lapis Menggunakan Metode Six Sigma\& Kaizen Serta Statistical Quality Control Sebagai Usaha Mengurangi Produk Cacat. Jurnal REKAVASI, Volume 6 No. 2, Desember 2018.

Fatkhurohman, Arief. 2016. Penerapan Kaizen Dalam Meningkatkan Efisiensi Dan Kualitas Produk Pada Bagian Banbury PT Bridgestone Tire Indonesia. Jurnal Administrasi Kantor, Volume 4 No. I, Juni 2016.
Gunawan, Udi. 2017. "Peningkatan Kapasitas Produksi Stearing Handle K81 Menggunakan Metode Quality Control Circle Di PT Dharma Polimetal". Program Studi Manajemen, STIE Pelita Bangsa. Bekasi 2017.

Heizer, J., \& Render, B. (2006). Operations management. (8th ed.). Upper Saddle River: Pearson Prentice Hall.

Lamsah, L. (2018). PENGARUH MOTIVASI DAN KEPUASAN KERJA TERHADAP KINERJA UKM. At-Tadbir: jurnal ilmiah manajemen, 2(2).

Lupiyoadi, Rambat. 2014. Manajemen Pemasaran Jasa,edisi 3. Jakarta: Salemba.

M.Sokovic, D.Pavlevic, K.Kem Pipan. 2010. Quality Improvement Methodologies - PDCA Cycle, RADAR Matrix, DMAIC and DFSS. Volemu 43, No. 1, p.476, November 2010.

Nasution, Nur. 2015. Manajemen Mutu Terpadu. Bogor: Ghalia Indonesia.

PT Astra Internasional. 2010. Buku Pedoman Astra Total Quality Control (ATQC). Jakarta: PT Astra International

Riyanto, OA Wahyu. 2015. Implementasi Metode Quality Control Circle Untuk Menurunkan Tingkat Cacat Pada Produk Alloy Wheel. JEMIS, Volume 3, No. 2, 2015.

Sallis, Edward. 2015. Total Quality Mmanagement in Education, Manajemen Mutu, Ahmad Ali Riyadi dan Fahrurozi, penerjemah. Yogyakarta: IRCiSoD. 